\title{
Los mártires en la realidad salvadoreña
}

\author{
P. José Maria Tojeira, S. J.
}

Hablar hoy de los mártires de la UCA exige ponerse siempre en un doble nivel. El nivel de lo que los mártires continúan diciéndonos hoy, en cuanto mártires, y el nivel de lo que hoy probablemente nos dirían. Hay en su recuerdo un mensaje permanente. Pero hay también, por la fuerza y la plenitud de vida que se dio en su existencia, una ensoñación permanente que brota de su recuerdo.

El mensaje de su martirio continúa siendo claro. La vida se hace hermosa y cobra sentido según la reciedumbre con que se viva. El existir "sin que la muerte al ojo estorbo sea", comprometidos plenamente con la dureza de la historia de nuestros países, garantiza la presencia en la vida después del término de la misma. Y no sólo una presencia individual, sino una permanencia intimamente unida a quienes dieron su vida con la misma generosidad y valentía. El Celebrador de la Palabra anónimo, asesinado por ser fiel a la predicación del Evangelio en su cantón, el niño de meses masacrado en El Mozote, la anciana degollada en el Sumpul, vuelven a la vida como recuerdo permanente a la luz de los casos más conocidos, sea Monsefíor Romero, los jesuitas de la UCA, Octavio Ortiz, etc. Es el triunfo de las víctimas que esclarecen desde su muerte la dignidad de todas las víctimas. Como la gran victima, Jesús de Nazaret, que desde su cruz nos sigue hablando del triunfo del amor, del diálogo y de la hermandad, frente a todo tipo de sociedad o institución que ponga como prioridad de hecho al poder, al dinero, al prestigio individual o a cualquier tipo de satisfacción egocéntrica. Incluso es el triunfo de las víctimas sobre la misma Iglesia, que como institución pecadora (que también lo es, además de santa) tiene la permanente "tentación de transformarse en un estado que persigue a sus enemigos" (Razinger J., 25 de septiembre de 1997).

Este mensaje de dignidad y entrega mantiene, evidentemente, su actualidad en la sociedad en que vivimos. Una sociedad como la nuestra necesita ser interpelada. Porque pone más esperanzas en las minorías pudientes que en las 
mayorlas empobrecidas, porque discrimina de hecho entre ricos y pobres en su sistema judicial, negando en la práctica (la igualdad ante la ley) lo que se afirma públicamente, porque se funciona determinando quiénes son superiores y quiénes inferiores tanto en sus derechos como en su realidad de personas. Y tanto la vida como la muerte de nuestros mártires constituye una clara interpelación: Rebeldes ante los convencionalismos sociales, solidarios con los empobrecidos y sus causas, críticos frente a todo lo que significara explotación, desprecio, marginación o dolor para los seres humanos, fueron asesinados por buscar caminos de esperanza, de paz construida sobre la justicia, de diálogo edificado sobre los derechos de los pobres. Mientras la injusticia permanezca, el recuerdo de ellos y de todas las víctimas de la injusticia sigue siendo una palabra necesaria. Cuando la injusticia desaparezca, "brillarán con chispas que se propagan en un cañaveral", y continuaremos recordándolos porque habrán sido parte de la victoria contra el mal.

Yo creo que hoy nuestros mártires nos seguirían hablando

de la pobreza. Porque sigue siendo una realidad dura en nuestro país a pesar de los resultados macroeconómicos y a pesar de las promesas de erradicarla.

Probablemente hoy, más que aspirar al martirio, debemos esperar un largo "gastarnos y desgastarnos" en el servicio de los mismos ideales de hermandad, justicia, erradicación de la pobreza, garantías a la dignidad de la persona humana. Y por ello también es bueno hacer el ejercicio, sin caer en imaginaciones arbitrarias, de lo que nuestros mártires nos dirían hoy. Y no sólo bueno, sino legírimo y necesario porque, como Jesús (y con él) desde su cruz, siguen hablándonos hasta el fin de la historia. Se trata de esos sueños soñados despiertos que nos incitan a las luchas nobles y que despiertan caminos nuevos de seguimiento del crucificado, en solidaridad con todos los crucificados de la historia.

Yo creo que hoy nuestros mártires nos seguirían hablando de la pobreza. Porque sigue siendo una realidad dura en nuestro pais a pesar de los resultados macroeconómicos y a pesar de las promesas de erradicarla. Y no sólo nos animarían a luchar contra la pobreza injusta, contra sus autores y contra las leyes, sistemas e instituciones que la mantienen, sino que nos exigirían al mismo tiempo realizar esta lucha desde la coherencia personal. Una coherencia personal que exige al menos austeridad. No se puede luchar contra la pobreza sońando con adquirir tantas riquezas como los explotadores tradicionales de nuestro pals. No podemos desear un imposible mundo (ni un imposible El Salvador) de todos ricos, porque ni el mundo ni El Salvador da para universalizar los niveles de vida de las clases medias altas de los países desarro- 
llados. Esos sueños de riqueza cada vez mayor no son más que mentiras de quienes mantienen este mundo con niveles de desproporción cada vez más enormes entre ricos y pobres. Ya en su tiempo Ellacurfa insistía en la civilización de la pobreza. Optar por niveles de vida austeros es hoy imprescindible para poder construir una sociedad justa, sin discriminación ni marginación de las mayorías.

Nos hablarían también de la igual dignidad de las personas. En este tiempo en el que se habla tanto de nuestra todavía débil democracia y de los pasos necesarios para fortalecerla, perseguir una adecuada igualdad ante la ley se convierte en un objetivo prioritario. No pode-

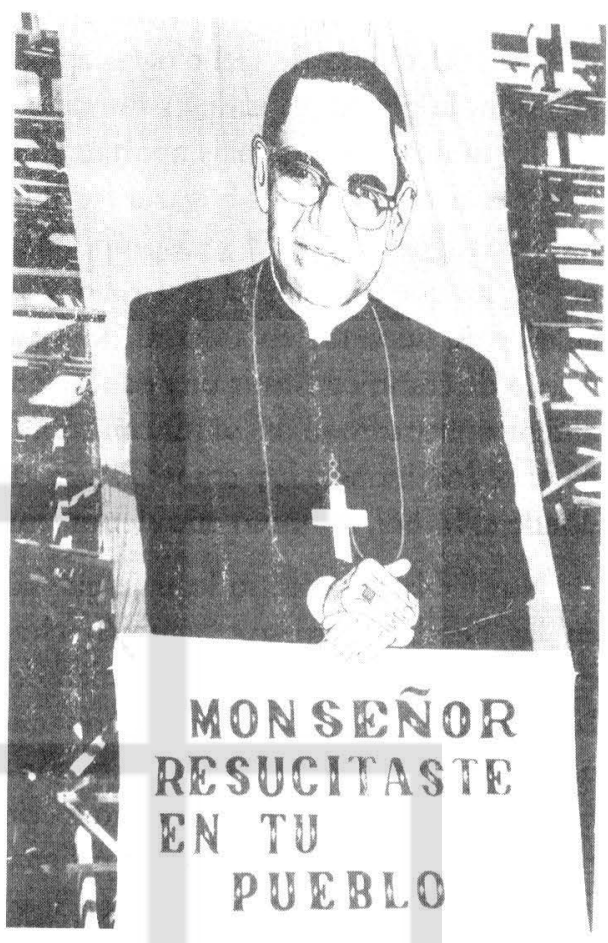
mos continuar — nos dirian- con estos espectáculos de impuestos sin pagar que se castigan con mayor o menor fuerza según la cercanía de los deudores con las autoridades gubernamentales. No se puede marginar a las radios comunitarias porque son pequeñas, en beneficio de una emisoras comerciales que se pasan todo el santo día diciéndole que compren productos de consumo a personas con bajo o casi nula capacidad de consumir. No se puede permitir que mientras los pequefios ladrones permanecen afios esperando ser juzgados, los grandes defraudadores del pals gocen de trato preferencial antes del juicio ( $y$ en esta etapa logran con frecuencia evitarlo), en el juicio y después del juicio. $Y$ probablemente nos regañarian por la tranquilidad con que dejamos pasar tanta palabrerla y contradicción en este campo.

Nos hablarían con un leguaje que sabría a sal de la tierra.

Esa sal que arde en las heridas, pero que también cicatriza, y que contribuye a darle a la existencia el sabor hondo y auténtico de la solidaridad, de la generosidad y de la esperanza.

Frente a la nula planificación del futuro o frente a los planes de nación tan cacareados, nos propondrían agendas de discusión sobre los principales problemas del país. Propuestas que trataran de reconciliar el crecimiento económico con el desarrollo social, el pluralismo con los derechos de los pobres, la 
ecología con la producción, la investigación cientifica (la cenicienta de nuestro pás) con el diseño de tecnologlas apropiadas. Propuestas que incluirian la dimensión de género en un país donde el machismo predomina, a pesar de que son las mujeres las que más aportan a la economía, al desarrollo y a la cultura (súmese el trabajo en el hogar a los diferentes trabajos que realizan las mujeres, investíguese quién es más importante en la transmisión de valores humanos sin los que es posible el desarrollo, $y$ añádasele el número de mujeres docentes en el pás, superior en total al de los hombres). Que incluirla también un diseño de cómo construir una educación en valores en una sociedad donde los antiguos escuadroneros pontifican sobre cuál es el futuro que más nos conviene a todos, donde los comerciantes de alcohol aspiran a la presidencia o donde el fútbol, hermoso entretenimiento, se confunde con el patriotismo.

Nos hablarian con un leguaje que sabría a sal de la tierra. Esa sal que arde en las heridas, pero que también cicatriza, y que contribuye a darle a la existencia el sabor hondo y auténtico de la solidaridad, de la generosidad y de la esperanza. Seguirían siendo provocadores y uniendo la inteligencia y el quehacer universitario a la provocación. Seguiráan siendo lo que eran, personalidades recias, abiertas al diálogo y críticas al mismo tiempo, sofiadores de la paz con justicia percibidos como peligrosos, luchadores capaces de hacer alianzas sin venderse, personas de bien. Si vivieran hoy; con su cansancio, con su envejecimiento y con sus problemas, seguirían siendo lo que son en el recuerdo: acicare, impulso, imaginación rigurosa y signo de esperanza. 